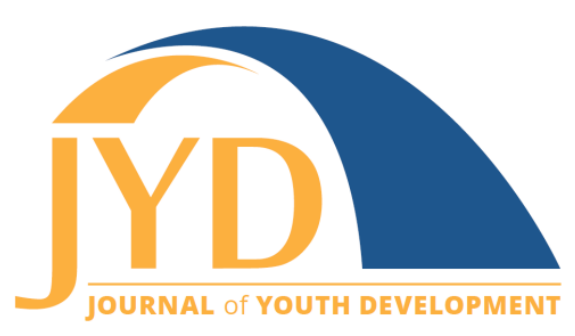

http://jyd.pitt.edu/ | Vol. 16 Issue 5 DOI 10.5195/jyd.2021.1196 | ISSN 2325-4017 (online)

\title{
Is Disruptive Innovation Impacting You?
}

\author{
Kia Harries \\ University of Minnesota Extension \\ kharries@umn.edu
}

\begin{abstract}
The intersection of leadership and innovation has led to disruptions in our lives from technology to social media and beyond. To a leader, the disruptions occur from new technology, situations like the pandemic, and how society puts things in motion. Innovations occur because of the ideas and questions that are shared. How you as a leader, a youth worker, or a community member, respond to the disruptions and innovations often impacts how you manage changes that occur in your work.
\end{abstract}

Key words: disruptive innovation, organizational leadership, opportunity

Our dilemma is that we hate change and love it at the same time. What we really want is for things to remain the same but get better. -Sydney Harris

Harris was an author and syndicated columnist in more than 200 daily newspapers who had a recurring feature titled, "Things I Learned En Route to Looking Up Other Things." His quote resonates with me because for the past 3 years, I've served as the President of the National Association of Extension 4-H Youth Development Professionals (NAE4-HYDP). As a long-time member of NAE4-HYDP, I know how the wheels of change move, as goals and aspirations are achieved at different paces. The past 3 years serve as a context for my reflections on how the COVID-19 pandemic brought significant change to my leadership journey.

As we face challenging times in our lives, we often express wishes about the improvements we want to see. We also express frustration when things are not as familiar to us because of the challenges we are experiencing. We often struggle with the tension between a wish for something better and the fear of that which is unfamiliar and uncomfortable.

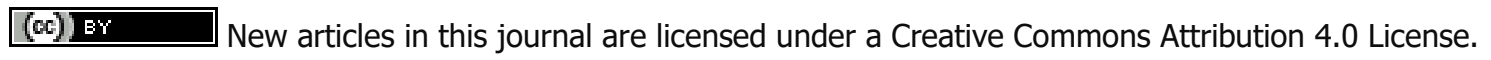
This journal is published by the University Library System, University of Pittsburgh and is cosponsored by the University of Pittsburgh Press. The Journal of Youth Development is the official peer-reviewed publication of the National Association of Extension 4-H Youth Development Professionals and the National AfterSchool Association. 


\section{Is Disruptive Innovation Impacting You?}

Just over 2 years ago I heard the term "disruptive innovation" for the first time from Dr. Scott Reed, then vice provost for University Outreach and Engagement and director of Oregon State University Extension Service. In the introduction to the topic of disruptive innovation, Dr. Reed spoke about the intersection of leadership and innovation and the mega forces serving as a disruption. Those disruptions come from changes in technology, questions about society, as well as the media. Some examples of these disruptions were given to help the learners grasp the concept, such as how cell phones have disrupted fixed-line telephones, how Netflix has disrupted Blockbuster, and how Airbnb has disrupted hotels. You might have your own list of ways technology, society or media has been a disrupter.

An interruption of service and supplies is a great example of a disruption. Over the past 18 months of the COVID-19 pandemic, we've seen a significant disruption to the services and supplies we know and have counted on. In some cases, we've been able to make adjustments and keep moving forward but at other times we've been forced to take a step back and rethink the path. Industry leaders have had to approach these supply chains with new ideas, changes to technology and production, as well as the staffing plan for employees. As we continue to see how the supply chain has been backed up or stalled on certain items, it takes creative thinking and new ideas to find solutions.

Industry and organizational leaders also had to look at the issue of remote work through a completely new lens. Whether it was the abrupt decision to send employees home at the beginning of the COVID pandemic or the need to balance the requests of employees who wanted a hybrid work opportunity, remote work was a large-scale disruption that was in need of an innovative response.

For me, the initial change to remote work brought a mix of questions and feelings: Did I have what I needed to do my work? How would my team interact with one another? How might my work be disrupted by what happens in my home (family members, pets, technology, etc.)? For some people, this change to an unknown remote work environment brought anxiety and stress. For others, it brought some welcome change, such as no commute or eating meals with the family.

As I consider remote work a full 18 months later, I see how the disruption has led to innovation in the work environment. There are new opportunities in place for employees to consider if (and how) they can work remotely, as well as criteria and expectations about what technology or equipment they need to do their work remotely. There is new and improved technology that continues to make remote work a possibility. The leaders in industry and organizations have 


\section{Is Disruptive Innovation Impacting You?}

had to think and work differently to make these disruptions work for their business but have also had to think about how the innovation could impact productivity.

Does it take just one action, or an event like a pandemic, to be a disruption? Does innovation come only on the heels of disruption? Let's explore this through a leadership perspective and put the words together in different orders, such as innovative disruptors or disruptive innovators. There are times that a leader (or a leadership team) has innovative ideas that disrupt a system or process. This might be difficult to implement or meet resistance because it is new and different and requires approaching things in new ways. Telemedicine during the pandemic would be a great example of an innovative disruption.

The disruptive innovation might be turning an idea completely upside down, it might even be unthinkable, but it leads to possibilities that can work. Consider a new leader who asks questions about the locations where people are working, which leads to a reorganization of geographical offices and assignments of work.

Can one person cause a disruption large enough to be noticed? In the case of leadership, I would say yes. Whether it's a new hire in an organization or the election of a new leader of an organization or association, I have to believe that can lead to a disruption. You might be asking what that disruption looks like and I believe it has to do with the ability to ask questions and bring new ideas to the table. I have seen this take shape when an organization hires a new leader who brings difficult questions to aid their learning. I also see it when new staff challenge existing staff to think about issues and programs in new ways. Consider the last time your business or organization hired a new leader. There may have been a period of learning and then, as their feet hit the ground, the disruptions came with questions about process or creative ideas for tackling problems. If your business or organization hasn't hired a new leader recently, consider what disruptions will occur when that does happen.

Leaders have always been recognized as change agents by trying new things and putting ideas forward. When coupled with this concept of disruptive innovation, leaders have to move from strategic planning to being able to execute programs and ideas quickly and with confidence.

I have seen an innovative disruption occur firsthand as a member of a national organization that elects new leadership each year. Disruption occurs every time someone new is elected because of their style of leadership, their organizational skills, and their communication styles, so the disruption isn't anything new. But the innovation, creativity, and questions brought with the newly elected leaders, in combination with the disruption, means change is likely to occur. 


\section{Is Disruptive Innovation Impacting You?}

As I reflect on this topic of disruptive innovation, a few questions come to mind that cause me to consider the impact of changing leadership on organizations:

- What if those in leadership asked one question that created disruption, just by the question itself, and then reverted back to what was comfortable?

- What happens to an organization that doesn't go through disruption?

- How does an organization look if it goes through disruption, but not innovation?

- Where will an organization find itself if nothing is passed on from former leaders?

- Who will be the next leaders if innovation and disruption are not encouraged?

Sometimes leaders want to take an organization in a new direction and struggle to find the team members who are willing to stretch their boundaries and get there. Sometimes leaders don't agree with everything the association or organization is doing, but the leadership role requires representing the larger organization or the greater good. Having leaders and a leadership team, who first bring the desire to make a difference and then bring courage to share their ideas, vision about what the future can hold, trust in the process, and the heart of a servant leader, means anything is possible.

As adult leaders, we sometimes forget that this cycle of disruption and innovation is fundamental to how youth learn and develop. As we work with youth to develop life skills, we are guiding and coaching them to try new things and problem solve for themselves. In a world where there are many disruptions and innovations occurring, our youth are facing these challenges and opportunities and these skills are needed more each day. We, as leaders in our field, should remember this and become more like youth in expecting, creating, and welcoming change and learning to work with it. If we do that, we may

- Become more open to innovation.

- Be open to the opportunities that disruption creates.

- Trust and participate actively in the process.

- Be willing to try, fail, and keep moving forward.

I opened my thought commentary with this quote from Sydney Harris: "Our dilemma is that we hate change and love it at the same time. What we really want is for things to remain the same but get better." I've come to accept that change is a fact of life. I've also come to realize that disruptive innovation brings about improvements and opportunities that I probably wouldn't have come to on my own and I am grateful for those who ask the questions and set new ideas in motion. 